Check for updates

Cite this: Chem. Commun., 2019, 55,7659

Received 6th May 2019,

Accepted 10th June 2019

DOI: $10.1039 / \mathrm{c} 9 \mathrm{cc} 03483 \mathrm{~h}$

rsc.li/chemcomm

\section{Inversion of donor-acceptor roles in photoinduced intervalence charge transfers $\dagger$}

\author{
Bruno M. Aramburu-Trošelj, (iD ab Paola S. Oviedo, ${ }^{\text {ab }}$ Ivana Ramírez-Wierzbicki, (iD ab \\ Luis M. Baraldo (D) ab and Alejandro Cadranel (iD *abc
}

\begin{abstract}
Upon MLCT photoexcitation, $\{($ tpy $) \mathrm{Ru}\}$ becomes the electron acceptor in the mixed valence $\left\{\left(\right.\right.$ tpy $\left.\left.^{-}{ }^{-}\right) \mathrm{Ru}^{\mathrm{III}-\delta}-\mathrm{NC}-\mathrm{M}^{\mathrm{Il}+\delta}\right\}$ moiety, reversing its role as the electron donor in the ground-state mixed valence analogue. Photoinduced mixed valence interactions can be tuned to obtain extended lifetimes and higher emission quantum yields, beneficial in supramolecular energy conversion schemes.
\end{abstract}

Traditionally, electronic communication in a wide variety of organic and inorganic molecular fragments with mixed valence configurations has been studied in the ground state. ${ }^{1-4}$ For example, $(\mathrm{d} \pi)^{6}(\mathrm{~d} \pi)^{5}$ bimetallic coordination complexes have been intensively investigated, ${ }^{5}$ and several theoretical models were developed to interpret their experimental properties such as their extended redox stability ${ }^{4}$ and the characteristics of the so-called intervalence charge transfer ground state absorption bands (GSIVCT). ${ }^{6}$ Besides the understanding of the basic factors controlling electron transfer events, one of the main goals in the field of mixed valency is to achieve molecular wirelike behavior that facilitates charge or energy migration along the length of the molecule. ${ }^{7-9}$ Less attention has been given to the same phenomena on the excited state, although, in the context of solar energy conversion schemes, such states and their reactivity are involved in the initial key steps. Thus, it is imperative to extend the study of photoinduced mixed-valence (PIMV) systems and their properties. ${ }^{10-19}$

It is important to make a distinction between excited state mixed valence (ESMV) and PIMV systems, the latter being a

\footnotetext{
${ }^{a}$ Universidad de Buenos Aires, Facultad de Ciencias Exactas y Naturales, Departamento de Química Inorgánica, Analitica y Quimica Física, Pabellón 2, Ciudad Universitaria, C1428EHA, Buenos Aires, Argentina.

E-mail: acadranel@qi.fcen.uba.ar

${ }^{b}$ CONICET - Universidad de Buenos Aires, Instituto de Química-Física de Materiales, Ambientes y Energía (INQUIMAE), Pabellón 2, Ciudad Universitaria, C1428EHA Buenos Aires, Argentina

${ }^{c}$ Department of Chemistry and Pharmacy \& Interdisciplinary Center for Molecular Materials (ICMM), Friedrich-Alexander-Universität Erlangen-Nürnberg,

Egerlandstr. 3, 91058 Erlangen, Germany

$\dagger$ Electronic supplementary information (ESI) available. See DOI: 10.1039/c9cc03483h
}

particular case of the former. ESMV is a more general concept, including also those systems where mixed valence interactions are already present in the ground state (GSMV). ESMV systems can result, for example, from photoexcitation on the GSIVCT band of a GSMV moiety, ${ }^{20-35}$ or from photoinduced energy transfer to GSMV-donor- or GSMV-acceptor-centered excited states. ${ }^{27,36,37}$ In contrast, the term PIMV is reserved only for those systems where GSMV interactions are absent. ${ }^{11-19,38}$ Therefore, the photogeneration of a PIMV excited state requires a previous event such as a photoinduced charge transfer that alters its configuration. The resulting system is a mixed valence complex with all its attributes, including photoinduced IVCT (PIIVCT) transitions and the possibility of charge delocalization. In contrast to GSMV or other ESMV species, in the PIMV system there is a remaining excited counterpart, i.e. the excited electron or the excited hole, that is not directly engaged in the mixed valence interactions. In the absence of a charge shift process that drives it away from the PIMV core, the excited counterpart modulates the properties of the PIMV species. For example, in a bimetallic $(\mathrm{d} \pi)^{6}(\mathrm{~d} \pi)^{6}$ ruthenium polypyridine, the photogenerated $(\mathrm{d} \pi)^{6}(\mathrm{~d} \pi)^{5}$ moiety includes a polypyridinic radical anion, whereas the oxidized $(\mathrm{d} \pi)^{6}(\mathrm{~d} \pi)^{5}$ system does not. Therefore, a detailed study of PIMV species in the presence of excited counterparts is required to gain control over electronic communication in the excited state.

Given that IVCT bands appear in the NIR region and are usually broad and weak, it is experimentally challenging to perform a systematic study based on the detection of transient PIIVCT bands, specially taking into account that some PIMV species are short-lived. ${ }^{39}$ In this contribution, we report on the study of a family of bimetallic complexes, with the formula $\left[\mathrm{Ru}(\mathrm{tpy})(\mathrm{bpy})(\mu-\mathrm{NC}) \mathrm{M}(\mathrm{CN})_{5}\right]^{2-}$, where $\mathrm{M}=\mathrm{Ru}(\mathrm{II})$, Os(II) or Fe(II) (Fig. 1), by means of vis-NIR transient absorption spectroscopy. We focus on the PIMV properties of the $\left\{\left(\mathrm{tpy}^{\bullet-}\right) \mathrm{Ru}^{\mathrm{III}-}-\mathrm{NC}^{\mathrm{N}} \mathrm{M}^{\mathrm{II}+\delta}\right\}$ fragments obtained upon photoexcitation, and we compare them with the GSMV properties of the related $\left\{\mathrm{Ru}^{\mathrm{II}+\delta}-\mathrm{NC}-\mathrm{M}^{\mathrm{III}-\delta}\right\}$ moieties obtained upon one electron oxidation of the reported complexes. 

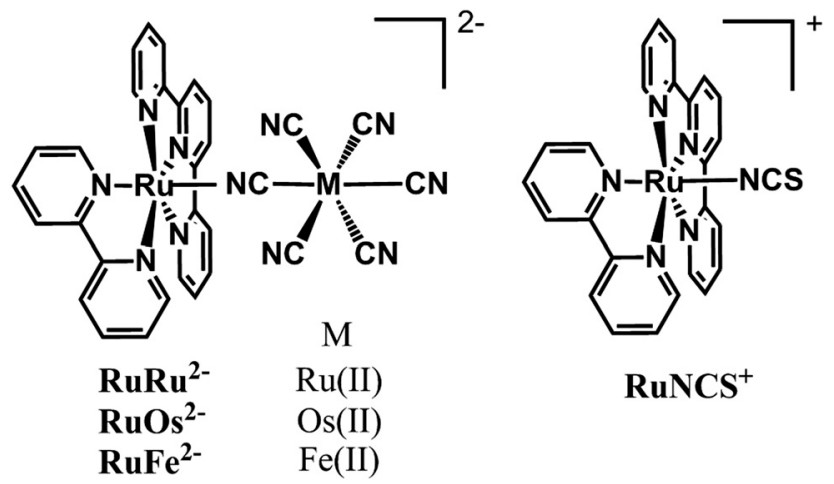

Fig. 1 Sketches of the complexes studied in this work.

The absorption spectra of $\mathbf{R u R u ^ { 2 - }}{ }^{2}, \mathbf{R u O s}^{2-}, \mathbf{R u F e} \mathbf{2}^{2-}$ and the reference monometallic complex $\mathbf{R u N C S}^{+}$are shown in Fig. S1 $(\mathrm{ESI} \dagger)$. In the bimetallic complexes, the visible absorptions are centered at the ruthenium polypyridinic fragment, since the hexacyanometallates absorb in the UV. ${ }^{40} \mathbf{R} \mathbf{u} \mathbf{R u}^{2-}$ and $\mathbf{R u O s}{ }^{2-}$ are emissive in water at room temperature, while $\mathbf{R u F e}^{2-}$ is not. ${ }^{41,42}$ The photophysical properties are summarized in Table 1 . The one-electron oxidized forms of the bimetallic complexes, this is $\mathbf{R u R u}^{-}$, RuOs $^{-}$and $\mathbf{R u F e}^{-}$, are $(\mathrm{d} \pi)^{6}(\mathrm{~d} \pi)^{5}$ mixed-valence species. They present GSIVCT absorption bands in the NIR (Fig. 2) whose energy correlates with the difference between the redox potentials of the metal-centered redox couples $\left(\Delta E_{1 / 2}\right.$ in Table 2$) .{ }^{41-43}$ The easier to reduce the $\left\{\mathrm{M}^{\mathrm{III}}(\mathrm{CN})_{6}\right\}$ fragment, the smaller the energy of the GSIVCT band. Therefore, these GSMV interactions, that result in a $\left\{(\right.$ tpy $\left.) \mathrm{Ru}^{\mathrm{II}+\delta}-\mathrm{NC}-\mathrm{M}^{\mathrm{III}-\delta}\right\}$ configuration, involve a $\{(\mathrm{tpy}) \mathrm{Ru}\}$ donor and a $\left\{\mathrm{M}(\mathrm{CN})_{6}\right\}$ acceptor. ${ }^{41,42}$

Excitation of $\mathbf{R u R u}^{2-}, \mathbf{R u O s}^{2-}, \mathbf{R u F e}^{2-}$ on their MLCT bands results in excited states that are also $(d \pi)^{6}(d \pi)^{5}$ mixed valence species but include a radical anionic polypyridine. These PIMV systems were photogenerated with a $19800 \mathrm{~cm}^{-1}(505 \mathrm{~nm})$ excitation, and $\mathbf{R u R u}^{2-}$ and $\mathbf{R u O s}^{2-}$ were studied, together with the reference RuNCS $^{+}$, utilizing nanosecond pump-probe vis-NIR transient absorption spectroscopy. $\mathbf{R} \mathbf{u F e} \mathbf{~}^{2-}$ required inspection in the picosecond timescale. In all these complexes, the excited state differential spectra do not present major changes in the corresponding timescales (please refer to the 3D maps in Fig. S4-S7, ESI $\dagger$ ). Due to their similar structure, the three bimetallic complexes present very close differential features upon photoexcitation, as shown in Fig. 3. A negative signal close to $20000 \mathrm{~cm}^{-1}$, mirroring GS absorptions, indicates the loss of GS population. Additionally, several positive signals are observed. The photoinduced

Table 1 Photophysical properties of $\mathrm{RuRu}^{2-}, \mathrm{RuOs}^{2-}, \mathrm{RuFe}^{2-}$ and RuNCS $^{+}$in water at room temperature

\begin{tabular}{lllll}
\hline Comp. & $\begin{array}{l}\nu_{\text {abs }} / 10^{3} \mathrm{~cm}^{-1} \\
\left(\lambda_{\mathrm{abs}} / \mathrm{nm}\right)\end{array}$ & $\begin{array}{l}\nu_{\mathrm{em}} / 10^{3} \mathrm{~cm}^{-1} \\
\left(\lambda_{\mathrm{em}} / \mathrm{nm}\right)\end{array}$ & $\phi_{\mathrm{em}} \times 10^{3}$ & $\tau_{\mathrm{em}} / \mathrm{ns}$ \\
\hline $\mathbf{R u N C S}^{+a}$ & $21.0(476)$ & $14.5(692)$ & 0.10 & 5.4 \\
$\mathbf{R u R u}^{2-b}$ & $20.6(486)$ & $14.1(707)$ & 1.42 & 16.6 \\
$\mathbf{R u O s}^{2-b}$ & $20.6(485)$ & $13.8(725)$ & 0.63 & 9.3 \\
$\mathbf{R u F e}^{2-c}$ & $21.3(470)$ & - & - & -
\end{tabular}

${ }^{a}$ This work. ${ }^{b}$ Ref. $42 .{ }^{c}$ Ref. 41.

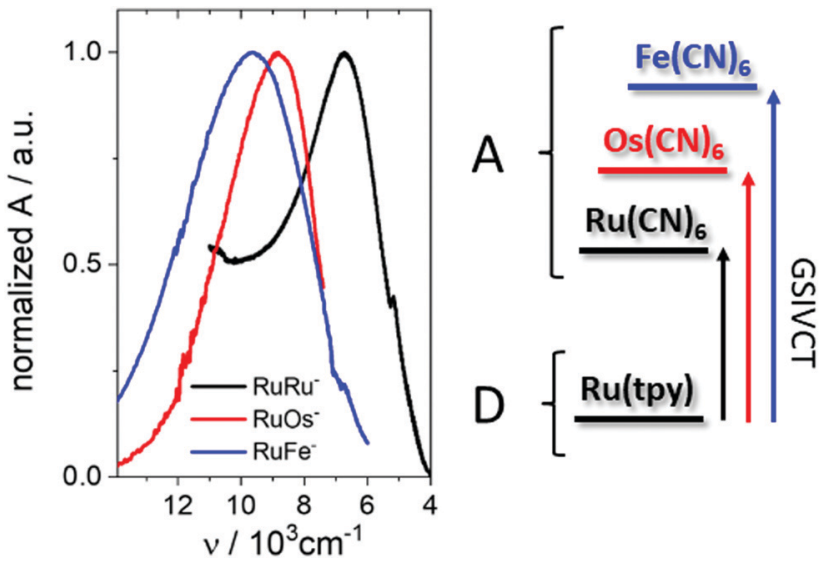

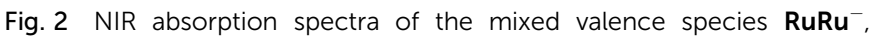
$\mathbf{R u O s}^{-}$and $\mathbf{R u F e}^{-}$in water at room temperature (left) and a scheme representing the energy levels of the orbitals involved in the GSIVCT transitions (right).

Table 2 Electrochemical and spectroscopic information for $\mathbf{R u R u}^{\mathbf{2}-}$, RuOs $^{2-}$ and $\mathbf{R u F e}^{2-}$ in water

\begin{tabular}{llllll}
\hline & $\begin{array}{l}E_{1 / 2}\left[\mathrm{M}^{\mathrm{III} / \mathrm{II}}\right. \\
\left.(\mathrm{CN})_{6}\right] / \mathrm{V}\end{array}$ & $\begin{array}{l}E_{1 / 2}\left[\mathrm{Ru}^{\mathrm{III} / \mathrm{II}}\right. \\
(\mathrm{tpy})] / \mathrm{V}\end{array}$ & $\Delta E_{1 / 2} / \mathrm{V}$ & $\begin{array}{l}\nu(\mathrm{GSIVCT}) / \\
10^{3} \mathrm{~cm}^{-1}\end{array}$ & $\begin{array}{l}\nu(\mathrm{PIIVCT}) / \\
10^{3} \mathrm{~cm}^{-1}\end{array}$ \\
\hline $\mathbf{R u R u}^{2-}$ & $0.61(150)^{b}$ & $0.94(120)^{b}$ & 0.33 & $6.7^{a}$ & 10.0 \\
$\mathbf{R u O s}^{2-}$ & $0.32(90)^{b}$ & $0.96(130)^{b}$ & 0.64 & $8.8^{b}$ & 7.8 \\
$\mathbf{R u F e}^{2-}$ & $0.18(80)^{c}$ & $0.88(80)^{c}$ & 0.70 & $9.7^{c}$ & 7.5
\end{tabular}

${ }^{a}$ This work. ${ }^{b}$ Ref. $42 .^{c}$ Ref. 41.

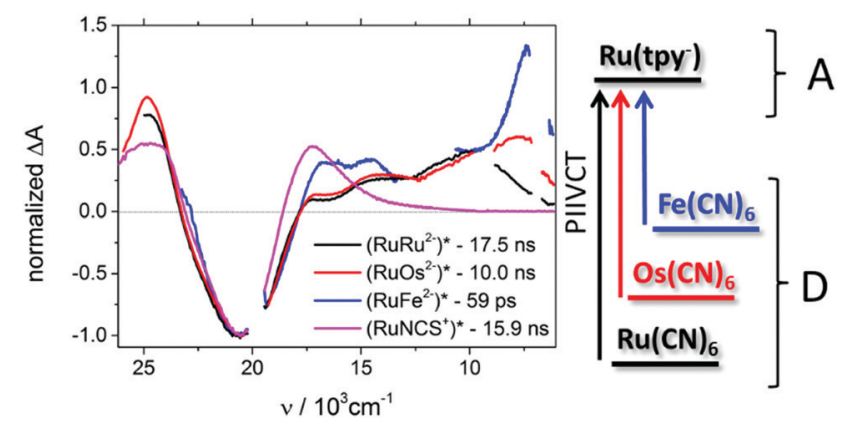

Fig. 3 Decay associated differential spectra of the PIMV excited state for $\mathbf{R u R u}^{2-}$ (black), RuOs ${ }^{2-}$ (red) and $\mathbf{R u F e}^{\mathbf{2}-}$ (blue) in water at room temperature (left), and a scheme representing the energy levels of the orbitals involved in the PIIVCT transitions (right). The differential spectrum of the ${ }^{3}$ MLCT state of RuNCS ${ }^{+}$in DMSO (pink) is also shown for comparison.

absorptions at $\nu>23000 \mathrm{~cm}^{-1}$ (peaking at $24800 \mathrm{~cm}^{-1}$ as observed in the nanosecond experiments) are ascribed to radical anion-centered $\pi^{*} \leftarrow \pi^{*}$ transitions, while those between 13000 and $17000 \mathrm{~cm}^{-1}$ correspond to radical anion-centered $\pi^{*} \leftarrow \pi^{*}$ transitions and $\mathrm{d} \pi(\mathrm{Ru}) \leftarrow \pi^{*}$ photoinduced LMCT bands. ${ }^{44,45}$ The energy of these signals remains essentially unchanged upon changing the nature of the $\mathrm{M}$ ion, although a strong photoinduced absorption in the spectrum of $\mathbf{R u F e}^{\mathbf{2}-}$ is detected at $16450 \mathrm{~cm}^{-1}$. We assign it as a $\mathrm{d} \pi(\mathrm{Ru}) \leftarrow \pi(\mathrm{CN})$ PILMCT transition from the cyanide bridge, which appears more to the red, and hence resolved from the bleach, for this complex since 
the iron moiety is the best donor in the series. A similar PILMCT band, $\mathrm{d} \pi(\mathrm{Ru}) \leftarrow \pi^{*}(\mathrm{NCS})$, appears at $17200 \mathrm{~cm}^{-1}$ in the monometallic reference RuNCS $^{+}{ }^{44}$ Intense photoinduced absorptions are also observed in the NIR, whose energy depend on the identity

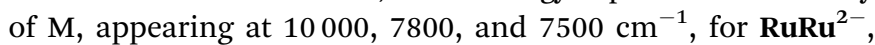
$\mathbf{R u O s}^{2-}$ and $\mathbf{R u F e}^{2-}$ respectively (Table 2 ). These resemble the NIR transient signals observed for related bimetallic complexes where a mixed-valence core is created upon photoexcitation, ${ }^{11-15,38,46}$ and are absent in $\left(\mathbf{R u N C S}^{+}\right)^{*}$ (Fig. 3). Therefore, they are assigned as PIIVCT bands.

The correlation of the PIIVCT energy with $\Delta E_{1 / 2}$ is reversed with respect to that of the GSIVCT energy. The easier to oxidize the $\left\{\mathrm{M}^{\mathrm{II}}(\mathrm{CN})_{6}\right\}$ fragment, the lower the energy of the PIIVCT band. This indicates that the PIMV interactions, that result in a $\left\{\left(\mathrm{tpy}^{\bullet-}\right) \mathrm{Ru}^{\mathrm{III}-\delta}-\mathrm{NC}-\mathrm{M}^{\mathrm{II}+\delta}\right\}$ configuration, involve a $\left\{\mathrm{M}(\mathrm{CN})_{6}\right\}$ donor and a $\{($ tpy $) \mathrm{Ru}\}$ acceptor. This is, the donor-acceptor roles are inverted in the PIMV state with respect to the ground state. The origin of this behavior is the presence of the tpy ${ }^{\bullet-}$ radical anion, that destabilizes the $\mathrm{d} \pi$ orbitals of the coordinated $\mathrm{Ru}$ ion.

It is notable how the relative intensity of the PIIVCT band grows from $\mathbf{R u R u ^ { 2 - }}$ to $\mathbf{R u F e}^{2-}$, reaching an intensity comparable to that of the bleached GS absorptions in $\mathbf{R u F e}^{\mathbf{2}-}$ (Fig. 3). The energy and shape of this band point to a high degree of delocalization for the excited hole. Solvent variation studies, which would help in classifying $\mathbf{R u F e}^{\mathbf{2}-}$ according to Robin-Day and Meyer, are hampered by the very low solubility of $\mathbf{R u F e}^{\mathbf{2}-}$ in organic solvents. Unfortunately, specific cyanide-solvent interactions preclude precise theoretical electronic structure calculations that could be useful at this point. However, in the related bimetallic complex $\left[\mathrm{Ru}^{\mathrm{II}}(\mathrm{tpy})(\mathrm{bpy})(\mu-\mathrm{CN}) \mathrm{Ru}^{\mathrm{II}}(\mathrm{py})_{4} \mathrm{Cl}\right]^{2+}$, where $\Delta E_{1 / 2}$ is $0.87 \mathrm{~V}$, the PIIVCT appears at $6900 \mathrm{~cm}^{-1}$ and presents an intensity comparable to the bleached GS absorption. All this evidence suggest a class III behavior for that bimetallic complex and $\mathbf{R u F e}^{\mathbf{2}-38}$ This behavior results from the combination of the strong coupling introduced by the cyanide bridge and the similitude in energy of the metallic ions, as observed previously for the ground state of mixed valence complexes. ${ }^{47-49}$

Global analyses of the transient absorption data for $\mathbf{R} \mathbf{u} \mathbf{R u}^{2-}$, RuOs $^{2-}$ and RuNCS ${ }^{+}$yielded lifetimes matching the emission lifetimes obtained by TCSPC (Table S1, ESI $\dagger$ ). For $\mathbf{R u F e}^{2-}$, two lifetimes were obtained. This is interpreted in terms of a hot MLCT state that cools down to the PIMV state in $1.9 \mathrm{ps}$, which depopulates in only 59 ps probably feeding a low-lying Fe-centered dd state. This state decays much faster than its feeding process, preventing an observable build-up. A similar process has been observed in the related bimetallic complex $\left[\mathrm{Ru}^{\mathrm{II}}(\mathrm{tpy})(\mathrm{bpy})(\mu \mathrm{NC}) \mathrm{Cr}^{\mathrm{III}}(\mathrm{CN})_{5}\right]^{-}$, where an energy transfer process from the MLCT to a low-lying Cr-centered dd state was observed to occur in 5 ps. $^{41,50}$

Interestingly, excited state electronic communication in the PIMV state has two important consequences. On one hand, $\mathrm{d} \pi$ orbitals are mixed within the bimetallic core, yielding a PIMV state that is stabilized with respect to the MLCT state in monometallic RuNCS ${ }^{+}$. This explains why $\mathbf{R u O s}^{2-}$, where orbital mixing is more important than in $\mathbf{R} \mathbf{R} \mathbf{R u}^{2-}$, emits at lower energies than the latter, although they have matching absorption spectra. Following these arguments, $\mathbf{R u F e}^{2-}$ would emit even more to the red, but this process is hindered by a fast quenching process. On the other hand, hole delocalization nests the potential energy surfaces of the excited and the ground states. This reduces the vibrational overlap, extending the lifetime and increasing the emission quantum yield of the PIMV state in comparison with the MLCT state in $\mathbf{R u N C S}^{+}$. As a consequence, $\mathbf{R u R u}^{\mathbf{2}-}$ emits one order of magnitude more efficiently than $\mathbf{R u N C S}^{+}$, with a threefold longer lifetime, regardless of additional decay pathways introduced by the second metallic ion and its coordination sphere. The emission quantum yield for $\mathbf{R u O s}^{2-}$ is only twice that for RuNCS ${ }^{+}$, with a two-fold longer lifetime, because in this case, spin-orbit coupling effects enhance non-radiative pathways to the ground state.

In conclusion, we have shown that the same donor and acceptor fragments engaged in mixed-valence interactions in the ground state of bimetallic ruthenium polypyridines, participate in analogous interactions in the excited state, but inverting their roles. The intensity of such interactions, evidenced by the PIIVCT transition, can have a strong and beneficial effect in their photophysical properties, lowering the energy of the PIMV state and extending its lifetime. Our results are relevant in terms of the understanding of the supramolecular photochemistry of PIMV systems of any type, and suggest that further studies will contribute to the development of more efficient chromophore-catalyst assemblies.

This work was supported by grants from the University of Buenos Aires (UBACyT 20020130100534BA and UBACYT 20020170100295BA), CONICET (PIP 112-20150100394CO) and ANPCyT (PICT 2013 00069). LMB and AC are members of the research staff of CONICET and BMAT is a postdoctoral fellow of the same institution. IRW acknowledges a scholarship "Estímulo a las Vocaciones Científicas" from Consejo Interuniversitario Nacional (EVC-CIN) and University of Buenos Aires. BMAT and AC acknowledge membership of ALN.

\section{Conflicts of interest}

There are no conflicts to declare.

\section{Notes and references}

1 J. Hankache and O. S. Wenger, Chem. Rev., 2011, 111, 5138-5178.

2 J. P. Launay, Chem. Soc. Rev., 2001, 30, 386-397.

3 K. D. Demadis, C. M. Hartshorn and T. J. Meyer, Chem. Rev., 2001, 101, 2655-2685.

4 R. F. Winter, Organometallics, 2014, 33, 4517-4536.

5 D. M. D'Alessandro and F. R. Keene, Chem. Rev., 2006, 106, 2270-2298.

6 D. M. D'Alessandro and F. R. Keene, Chem. Soc. Rev., 2006, 424-440.

7 S. Saha Roy, A. Sil, D. Giri, S. Roy Chowdhury, S. Mishra and S. K. Patra, Dalton Trans., 2018, 47, 14304-14317.

8 D. Bu, Y. Xiong, Y. N. Tan, M. Meng, P. J. Low, D. Bin Kuang and C. Y. Liu, Chem. Sci., 2018, 9, 3438-3450.

9 D. K. James and J. M. Tour, Top. Curr. Chem., 2005, 257, 33-62.

10 T. V. Duncan, I. V. Rubtsov, H. T. Uyeda and M. J. Therien, J. Am. Chem. Soc., 2004, 126, 9474-9475.

11 K. Kalyanasundaram and M. K. Nazeeruddin, Inorg. Chim. Acta, 1994, 226, 213-230. 
12 C. A. Bignozzi, R. Argazzi, J. R. Schoonover, K. C. Gordon, R. B. Dyer and F. Scandola, Inorg. Chem., 1992, 31, 5260-5267.

13 K. Matsui, M. K. Nazeeruddin, R. Humbphry-Baker, M. Grätzel and K. Kalyanasuadaram, J. Phys. Chem., 1992, 96, 10587-10590.

14 K. Kalyanasundaram, M. Grätzel and M. K. Nazeeruddin, Inorg. Chem., 1992, 31, 5243-5253.

15 C. A. Bignozzi, R. Argazzi, C. Chiorboli, F. Scandola, R. B. Dyer, J. R. Schoonover and T. J. Meyer, Inorg. Chem., 1994, 33, 1652-1659.

16 C. N. Fleming, D. M. Dattelbaum, D. W. Thompson, A. Y. Ershov and T. J. Meyer, J. Am. Chem. Soc., 2007, 129, 9622-9630.

17 D. M. Dattelbaum, C. M. Hartshorn and T. J. Meyer, J. Am. Chem. Soc., 2002, 124, 4938-4939.

18 C. Kreitner, M. Grabolle, U. Resch-Genger and K. Heinze, Inorg. Chem., 2014, 53, 12947-12961.

19 L. De Cola, V. Balzani, F. Barigelletti, L. Flamigni, P. Belser, A. vos Zelewsky, M. Frank and F. Vögtle, Inorg. Chem., 1993, 32, 5228-5238.

20 G. C. Walker, P. F. Barbara, S. K. Doorn, Y. Dong and J. T. Hupp, J. Phys. Chem., 1991, 95, 5712-5715.

21 D. H. Son, P. Kambhampati, T. W. Kee and P. F. Barbara, J. Phys. Chem. A, 2002, 106, 4591-4597.

22 D. G. Evans, A. Nitzan and M. A. Ratner, J. Chem. Phys., 1998, 108, 6387-6393.

23 P. J. Reid, J. Phys. Chem., 1995, 99, 2609-2616.

24 D. A. V. Kliner, K. Tominaga, G. C. Walker and P. F. Barbara, J. Am. Chem. Soc., 1992, 114, 8323-8325.

25 K. Tominaga, D. A. V. Kliner, A. E. Johnson, N. E. Levinger and P. F. Barbara, J. Chem. Phys., 1993, 98, 1228-1243.

26 P. Kambhampati, D. H. Son, T. W. Kee and P. F. Barbara, J. Phys. Chem. A, 2000, 104, 10637-10644.

27 M. T. Indelli and F. Scandola, J. Phys. Chem., 1993, 97, 3328-3332.

28 B. P. Macpherson, P. V. Bernhardt, A. Hauser, S. Pagès and E. Vauthey, Inorg. Chem., 2005, 44, 5530-5536.

29 C. Lambert, M. Moos, A. Schmiedel, M. Holzapfel, J. Schäfer, M. Kess and V. Engel, Phys. Chem. Chem. Phys., 2016, 18, 19405-19411.

30 W. Kim, E. Edri and H. Frei, Acc. Chem. Res., 2016, 49, 1634-1645.

31 J. B. G. Gluyas, A. N. Sobolev, E. G. Moore and P. J. Low, Organometallics, 2015, 34, 3923-3926.
32 S. K. Doorn, P. O. Stoutland, R. B. Dyer and W. H. Woodruff, J. Am. Chem. Soc., 1992, 114, 3133-3134.

33 S. K. Doorn, R. B. Dyer, P. O. Stoutland and W. H. Woodruff, J. Am. Chem. Soc., 1993, 115, 6398-6405.

34 Y.-J. Chen, O. S. Odongo, P. G. McNamara, K. T. Szacilowski and J. F. Endicott, Inorg. Chem., 2008, 47, 10921-10934.

35 D. F. Watson, H. S. Tan, E. Schreiber, C. J. Mordas and A. B. Bocarsly, J. Phys. Chem. A, 2004, 108, 3261-3267.

36 C. A. Bignozzi, M. T. Indelli and F. Scandola, J. Am. Chem. Soc., 1989, 111, 5192-5198.

37 C. A. Bignozzi, O. Bortolini, C. Chiorboli, M. T. Indelli, M. A. Rampi and F. Scandola, Inorg. Chem., 1992, 31, 172-177.

38 P. S. Oviedo, G. E. Pieslinger, L. M. Baraldo, A. Cadranel and D. M. Guldi, J. Phys. Chem. C, 2019, 123, 3285-3291.

39 C. Lambert, R. Wagener, J. H. Klein, G. Grelaud, M. Moos, A. Schmiedel, M. Holzapfel and T. Bruhn, Chem. Commun., 2014, 50, 11350.

40 J. J. Alexander and H. B. Gray, J. Am. Chem. Soc., 1968, 90, 4260-4271.

41 A. Cadranel, P. Alborés, S. Yamazaki, V. D. Kleiman and L. M. Baraldo, Dalton Trans., 2012, 41, 5343-5350.

42 A. Cadranel, B. M. Aramburu Trošelj, S. Yamazaki, P. Alborés, V. D. Kleiman and L. M. Baraldo, Dalton Trans., 2013, 42, 16723-16732.

43 P. Alborés, L. D. Slep, T. Weyhermüller and L. L. M. Baraldo, Inorg. Chem., 2004, 43, 6762-6773.

44 A. Cadranel, P. Oviedo, G. E. Pieslinger, S. Yamazak, V. D. Kleiman, L. M. Baraldo and D. M. Guldi, Chem. Sci., 2017, 8, 7434-7442.

45 A. Cadranel, G. E. Pieslinger, P. Tongying, M. K. Kuno, L. M. Baraldo and J. H. Hodak, Dalton Trans., 2016, 45, 5464-5475.

46 D. M. Dattelbaum, K. M. Omberg, J. R. Schoonover, R. L. Martin and T. J. Meyer, Inorg. Chem., 2002, 41, 6071-6079.

47 X. Ma, C.-S. Lin, X.-Q. Zhu, S.-M. Hu, T.-L. Sheng and X.-T. Wu, Angew. Chem., Int. Ed., 2017, 56, 1605-1609.

48 G. E. Pieslinger, P. Alborés, L. D. Slep and L. M. Baraldo, Angew. Chem., Int. Ed., 2014, 53, 1293-1296.

49 G. E. Pieslinger, B. M. Aramburu-Trošelj, A. Cadranel and L. M. Baraldo, Inorg. Chem., 2014, 53, 8221-8229.

50 A. Cadranel, J. E. Tate, P. S. Oviedo, S. Yamazaki, J. H. Hodak, L. M. Baraldo and V. D. Kleiman, Phys. Chem. Chem. Phys., 2017, 19, 2882-2893. 